\title{
A Psychological Account of the Unique Decline in Anti-Gay Attitudes
}

\author{
Victor Kumar (Boston University) \\ Aditi Kodipady (Boston College) \\ Liane Young (Boston College)
}

\begin{abstract}
Anti-gay attitudes have declined in the U.S. The magnitude, speed, and demographic scope of this change have been impressive especially in comparison with prejudice against other marginalized groups. We develop a psychological account of the unique decline in anti-gay bias in the context of important cultural and political conditions. We highlight two key psychological mechanisms: interpersonal connection and social category classification. First, many people have discovered that a close friend, family member, or admired individual is gay, motivating them to identify the harm and discrimination faced by the individual they know, and catalyzing moral consistency reasoning such that they generalize this interpersonal insight to strangers. Second, many people have taken an essentialist stance toward social categories, including sexual orientation, leading them to infer that being gay is genetically determined and not subject to free choice or moral responsibility, nor mutable and worth attempting to change. We contrast this with the relationship between essentialism and attitudes toward women and people of color, and provide an account of the difference. This psychological account has implications for the future decline of anti-gay attitudes, in the U.S. and other countries, along with the nascent decline of anti-trans attitudes.
\end{abstract}




\section{Introduction}

Over the last fifty years or so, and especially over the last few decades, the U.S. and many other societies have undergone a large, rapid, and broad decline in anti-gay attitudes. The magnitude, speed, and demographic scope of this change render it unique, distinguishing it from contemporaneous declines in negative attitudes toward other marginalized groups, such as racial/ethnic minorities and women. The historic societal shift in anti-gay attitudes is unprecedented, even profound, and demands detailed theoretical and empirical analysis. A sound analysis may also yield practical, policy-relevant insights into effective strategies for continuing to reduce the prevalence and intensity of anti-gay attitudes, in the U.S. and other countries, along with analogous strategies for fostering progressive attitude change toward other marginalized groups in the LGBTQ community.

In this article we develop a new explanatory theory: we identify a pair of complex psychological mechanisms that underlie the relatively large, rapid, and broad decline in anti-gay attitudes among many Americans. Our theory draws on existing psychological research on anti-gay attitudes, psychological research on attitudes toward other marginalized groups, and philosophical theory. The first step in this explanatory project is to characterize in detail the decline of anti-gay attitudes and its unique features (section 2). Next, we explain the decline by appealing to the collective force of psychological mechanisms that fall into two key categories: interpersonal connections (section 3) and social category classification (section 4). In the end, we will be in a position to consider the extent to which our explanatory theory can be projected into the future, extended to a broader range of societies, and applied to other marginalized groups, especially transgender people (section 5). 


\section{A Unique Decline}

In the middle of the $20^{\text {th }}$ century it was extraordinarily difficult to be gay in America. Openly gay people were regularly disowned by their families, ostracized by their religious communities, and fired by their employers without any available legal recourse. Being gay was an invitation to stigma, hostility, and violence. The best option, for some individuals, was still abysmal: to lead a closeted life in which they are unable to express a fundamental aspect of their identity to intimates and even to themselves. For open and closeted gay people alike, rates of depression and suicide were high, especially for vulnerable gay youth (Gibson, 1989).

Over the course of several decades, however, gay men and women have experienced a dramatic improvement in their life prospects. To begin with, medical discrimination against gay people has declined in the past fifty years. After removing homosexuality from the DSM's list of diagnostic categories in 1973 (Spitzer, 1981), the medical community has become far less prone to pathologize homosexuality (Drescher, 2015). Nineteen U.S. states have banned conversion therapy (Zaveri, 2020). Alongside these changes in the medical field, many oppressive, anti-gay laws have been repealed or superseded, for example, via Supreme Court rulings on adoption rights (V. L. v. E.L., 2016; Pavan v. Smith, 2017) and legislation that expanded the definition of hate crime to include actual or perceived discrimination or violence on the basis of gender, sexual orientation, gender identity, or disability (Matthew Shepard and James Byrd Jr. Hate Crimes Prevention Act, 2009). In 2015 the U.S. joined dozens of other countries by legalizing marriage equality (Obergefell v. Hodges, 2015). In addition to medicine and the law, there have been steps towards progress in traditionally conservative U.S. institutions. In 1993 the Department of Defense issued a directive that protected closeted gay people from discrimination; in 2011 "Don’t Ask, Don’t Tell” was abandoned, and openly gay people were permitted to serve 
in the military. Lastly, American religious institutions have become more welcoming to gay congregants, and some denominations have explicitly permitted gay people to serve as ministers (National Congregations Study, 2012). ${ }^{1}$

Alongside the institutional reforms reviewed above, straight people have gradually reformed their behavior. A smaller proportion of openly gay people face explicit ostracism and discrimination. For instance, the use of anti-gay slurs on social media is less common (Wells, 2012), and homophobic slurs are also culturally less acceptable in other contexts. On the whole, behavioral reforms have accumulated, leading to broader cultural changes, for example, in the media and politics. LGBTQ characters are more common on TV, up to $10.2 \%$ in the $2019-20$ season (GLAAD, 2019). Between 2019 and 2020, there has been a 21\% increase in the number of LGBTQ representative officials (Victory Institute, 2020). ${ }^{2}$ Indeed, a leading contender for the 2020 Democratic presidential nomination, Pete Buttigieg, publicly identified as a gay man.

Nevertheless, hate crimes against gay men and and women saw a slight increase in the past decade (FBI, 2019). It is possible that this is due to gay people being in an environment where they are more comfortable reporting hate crimes and where those reports are better documented. Regardless, this recent uptick also serves as a crucial reminder that progressive change does not always result in consistent material improvement in the lives of marginalized communities. Furthermore, progressive changes are often fragile. For example, it is possible that the US Supreme Court will reverse course on marriage equality (Totenberg, 2020). Institutional and behavioral reforms have not gone far enough, especially for many Black, Indigenous, and trans populations of gay people. For example, Black gay and transgender people experience

\footnotetext{
${ }^{1}$ The percentage of church congregations in the US that allowed openly gay people to hold full-fledged membership increased from $37.4 \%$ in $2006-07$ to $48 \%$ in 2012 , and the percentage that allowed them in positions of voluntary leadership increased from $17.8 \%$ to $26.5 \%$ within the same time period (National Congregations Study, 2012). ${ }^{2}$ Of these, $54 \%$ are gay men and $30 \%$ are lesbians -- and $94 \%$ are cis, and $77 \%$ are white (Victory Institute 2020 ).
} 
higher rates of housing insecurity and lower access to healthcare than both straight Black people and gay White people because of institutionalized racism and anti-gay/anti-trans discrimination in the housing and healthcare sectors (Moodie-Mills, 2012). Nonetheless, changes like those we have listed arguably represent one of the most significant episodes of moral progress in living memory.

Progressive improvements in behavior and institutional structure are important in their own right, but they are also entangled with the decline of anti-gay attitudes (Ofosu et al., 2019). Fewer straight people nowadays feel antipathy toward gay men and women. Americans are less likely to believe that being gay is immoral. Furthermore, they are less likely to support anti-gay positions on various social issues. For example, a majority of Americans (63\%) believe that gay couples should be allowed to adopt children (Gallup, 2014), and 58\% of Americans think that the military should welcome gay soldiers within its ranks (Pew, 2010). The decline of anti-gay attitudes spans a wide range of emotions, beliefs, and other psychological attitudes.

In this article, we focus on attitude change, in the broadest sense, rather than behavioral and institutional reforms that are also essential to and signatures of moral progress. Before developing a psychological theory that helps explain the historic change in attitudes, however, we need a characterization of its unique features.

One well-studied proxy for the decline in anti-gay attitudes is the shifting number of people who favor or oppose same-sex marriage. For example, the Pew Research Center conducts yearly polls in which they ask Americans whether their society should accept same-sex marriage (Pew, 2019). In 2001, 57\% of adults opposed same-sex marriage; this number dropped to $31 \%$ by 2019. Conversely, in 2001 , only $35 \%$ of adults favored same-sex marriage; this number rose to $61 \%$ by 2019 . The data from Pew are corroborated by other polls, which collectively illustrate 
three features of the decline in anti-gay attitudes (CBS News, 2016; Gallup, 2017; Public Religion Research Institute, 2019). First, the change has been large. The proportion of Americans who opposed same-sex marriage dropped from roughly $57 \%$ to $31 \%$. Second, the change has been rapid. Opinions changed in less than 20 years. Third, the data from Pew illustrate that the decline in anti-gay attitudes has been broad. That is, over approximately the same period of time, Pew found that more Americans accept same-sex marriage across demographic groups related to political party, religious affiliation, race, gender, and age. From 2001 to 2019, the proportion of Democrats who accept same-sex marriage increased (45\% to $75 \%$ ), but the proportion of Republicans also increased (23\% to $44 \%$ ). Religiously unaffiliated people became more accepting (61\% to $79 \%$ ), but so too did White mainline Protestants (38\% to $66 \%$ ), Catholics (40\% to $61 \%$ ), Black Protestants (30\% to 44\%), and White evangelical Protestants (13\% to $29 \%)$. Same-sex marriage was accepted by a higher proportion of White people (34\% to $62 \%$ ), Black people (32\% to $51 \%$ ), and Hispanic people (42\% in 2006 to $58 \%$ ). Women became more accepting (38\% to $66 \%)$, as did men (32\% to $57 \%)$. Finally, acceptance climbed among Millennials (51\% to 74\%), Generation X (49\% to 58\%), Baby Boomers (32\% to $51 \%)$, and the Silent Generation ( $21 \%$ to $45 \%)$. Therefore, and, perhaps, contrary to expectations, Americans' increasing support for same-sex marriage has not been driven exclusively by change among a limited subset of people, such as those who are left-wing, irreligious, or young (Charlesworth \& Banaji, in press).

Another well-studied proxy for the wide-ranging decline in anti-gay attitudes is implicit bias. Implicit biases began to be studied decades ago. The implicit association test (IAT) was launched in 1998 (Greenwald et al., 1998) to study implicit attitudes connected to race, gender, age, and other social categories (Nosek et al., 2002), including sexual orientation (Steffens \& 
Buchner, 2003; Steffens, 2005; Jellison et al., 2004). At the time, anti-gay implicit biases were among the strongest of those studied. However, relying on data from over three million American respondents, Charlesworth and Banaji report that these biases are now among the weakest (Charlesworth \& Banaji, 2019; in press). The magnitude and breadth of anti-gay implicit bias in the U.S. has shrunk more quickly than any other implicit bias studied, shifting by $33 \%$ just over the last decade. Furthermore, Charlesworth and Banaji (in press) report that implicit and explicit anti-gay attitudes have declined within diverse demographic groups, e.g., for both men and women, Whites and Blacks, young and old.

These findings on implicit and explicit anti-gay bias align with the polling results on same-sex marriage reviewed above. The findings on implicit and explicit bias further enable a precise characterization of the magnitude, speed, and scope of the decline in anti-gay attitudes; anti-gay implicit biases can be directly compared to other implicit biases. For example, Charlesworth and Banaji (2019, in press) report that implicit biases associated with race and gender have also declined over the same period of time but, in addition to these changes being less linear, they have declined only by about half as much.

At this stage, it is important to register a qualification about the decline of anti-gay attitudes. Overall, the decline has benefited many gay people who are no longer targets of prejudice and discrimination. However, progressive changes have not benefited everyone equally. In particular, gay people who are white, upper-class, cisgender, and straight-passing have enjoyed a disproportionate share of the benefits. Gay people who are members of other marginalized categories have not gained as much approval and acceptance from society. In short, the shift in anti-gay attitudes reflects a general pattern of intersectional disadvantage. Gay people who are members of multiple minority groups (e.g., gay people of color) experience increased 
stigmatization, discrimination, and worse health outcomes (Cyrus, 2017). Thus, relatively privileged members of a marginalized group have benefited the most from progressive attitude change. One possible reason for this disparity is that cultural represenations of gay people in television and film tend to be White, upper-class, and cisgender (GLAAD, 2021). Another dimension of this phenomenon is that the gay people who have benefited the most from these changes in attitude are those whose lifestyle approximates widely-held, traditional American values of family and comportment (Puar, 2018). Many people have not accepted gay individuals who are polyamorous, or who are sex workers, or whose lifestyles are otherwise non-conforming. (It may also be worth noting that, while the same people may not accept straight individuals who are polyamorous, or who are sex workers, biases in the domain of sexuality may interact multiplicatively to increase bias, or else obscure bias, e.g., someone may claim that they dislike the fact that a gay individual is polyamorous and not that they are gay.) Thus, while progress has been made, it also has not gone far enough. In spite of the decline in anti-gay attitudes, more thoroughgoing eradication of anti-gay prejudice is clearly necessary.

The explanation for the dramatic (if selective) decline in anti-gay attitudes, implicit and explicit, is sure to be multi-factorial. One important set of mechanisms is political: activism, protests, and identity politics. Another set is cultural: public relations, pro-gay spokespersons, and popular culture in music, film, and fashion. However, both sets of political and cultural mechanisms fail to fully explain the unique features of the decline. First of all, if only these mechanisms were at play then we should observe a large impact on attitudes within some demographic groups and little to zero impact within others. For example, young people and liberals tend to have much greater exposure to activism and popular culture. So, whereas these factors can explain why young people and liberals have undergone a larger and faster decline in 
anti-gay attitudes, by themselves they cannot explain that declines (although less rapid) have also been observed among older people and conservatives. Furthermore, political and cultural mechanisms both seem to have been at play in reducing racist and sexist attitudes as well. Therefore, appealing to politics and culture alone cannot explain why the decline of anti-gay attitudes has been so much larger, faster, and broader. We do not deny that various political and cultural mechanisms have played (and continue to play) an important role in the decline of anti-gay attitudes. However, in the following sections we will argue that a pair of interrelated psychological mechanisms help explain the unique features of the decline. In general, psychological changes unfold in concert with political and cultural changes (see Bronfenbrenner, 1992). Various political and cultural factors will serve as necessary conditions in our explanatory theory; they help explain why anti-gay attitudes unfolded recently, after centuries of stasis. But our principal focus will be on psychological factors.

Some researchers believe that the decline of anti-gay attitudes is driven largely by generational turnover. There is some truth to this idea. Available evidence suggests that younger generations are less likely to have negative attitudes toward gay people and related issues. For example, Pew data show that $79 \%$ of people under the age of 30 support same-sex marriage, while only $52 \%$ of people who are 50 years or older share this view (Pew, 2017). However, the polling and implicit bias findings reviewed above show that older generations have also changed their minds. The psychological mechanisms that we will identify explain attitude change among both younger and older populations, revealing a truly widespread shift in the attitudes of society. We will argue that the decline of anti-gay attitudes has been larger, faster, and broader than other progressive attitude changes in virtue of interpersonal connections (section 3) and social category 
classification (section 4). Over the next two sections, we will go through each mechanism in turn.

\section{Psychological Mechanism I: Interpersonal Connections}

We propose that interpersonal connections have played an outsized role in the decline of anti-gay attitudes. By this, we simply mean relationships that involve intimacy or admiration, such as between parent and child, siblings, friends, or celebrities and fans. In fact, many of the intervention strategies recommended to reduce bias involve favorable intergroup contact that fosters interpersonal connections (Dovidio et al., 2017; Onyeador et al., 2020). We will argue that interpersonal connections have driven a relatively large, rapid, and broad change in attitudes due to differences between sexual orientation and other social identities, such as race and ethnicity. Because homosexuality is a diffuse, invisible (or at least easily concealable) trait, straight people are likely to have friendships, family links, and other interpersonal connections, with people whom they initially did not know are gay. By contrast, for example, White Americans are less likely to have interpersonal connections with people who are members of marginalized racial or ethnic outgroups. In addition, it is unlikely for a person's racial and ethnic identity to be unknown at the outset of a relationship. Put simply, then, the first psychological mechanism at play in the decline of anti-gay attitudes implicates the large and growing number of individuals with interpersonal connections to gay people (Pew, 2016). We propose that these individuals are better equipped, and more motivated, to reform negative attitudes directed toward close and admired others ("local changes," described in 3.1). Some of these individuals then reformed their attitudes towards a wider range of gay people via moral reasoning and generalization ("general changes," described in 3.2). We note that past research also suggests that 
closer interpersonal connections between straight and gay people predict lower anti-gay prejudice (MacInnis et al., 2017, Herek \& Capitanio, 1996; Herek \& Glunt, 1993; Lewis, 2011; Wittlin et al., 2019), but this research does not identify the explanatory psychological mechanism that we unpack in this article. In the rest of this section we will dig into the details of the underlying psychological mechanism, first describing local changes in attitudes toward close and admired others, and then turning to general changes in attitudes toward strangers.

\subsection{Local Changes}

Unfortunately, many gay people have been forced to conceal their sexuality. An important catalyst in the decline of anti-gay attitudes is the growing number of gay Americans who chose to live open and candid lives during the second half of the $20^{\text {th }}$ century and early decades of the $21^{\text {st }}$ century, beginning in major urban centers. Consequently, more and more people discovered a valued family member or friend to be gay. In general, people are disposed to empathize and sympathize - more easily and intensely—with people they are in close interpersonal relationships with (Krienen et al., 2010; Zaki, 2014). They are better able to appreciate that their gay family member or friend is harmed, that their liberty is needlessly curtailed, that their dignity is threatened, etc. This does not always happen. Sometimes, tragically, the discovery that a family member or friend is gay leads to violence or rejection. However, through attending to the impact on their family member or friend, many straight people started to notice and care that formal laws and informal norms are anti-gay, that many people exhibit anti-gay behavior through overt discrimination and more subtle microaggressions, and that gay people face prejudice from religious organizations, medical professionals, the media, schools, and other social institutions. Just as important, as we explore further below, people are likely to have strong positive beliefs 
about close others, e.g., that they are good, moral people. In this way, interpersonal relationships highlight individuals as having both "patiency" or great potential for experience, specifically, suffering and "agency", specifically, moral agency or the capacity for good (Schein \& Gray, 2018; Gray et al., 2012; Yam et al., 2019).

But why exactly did interpersonal connections help bring about, in relative terms, a large, rapid, and broad change in attitudes? One reason is that sexual orientation, whatever its putative genetic causes, has a similar distribution across human lineages. Being gay is a "horizontal" identity, rather than a "vertical" one (Solomon, 2012). So, it is more-or-less randomly distributed across the human population. Consequently, people with different political leanings, different religious affiliations, and different racial/ethnic identities are approximately as likely as one another to be gay, and, likewise, to develop a close relationship with someone who is gay. Gay and straight people are therefore likely to find themselves in close interpersonal relationships with one another. Compare the situation for Black and White people in America, where de facto segregation remains intense in neighborhoods, schools, and employment. Black and White people are far less likely to find themselves in close interpersonal relationships; this sustains anti-Black prejudice (Anderson, 2010; Kunst, Onyeador \& Dovidio, 2019). An especially notable contrast with race is that many straight people discover that family members are gay. Furthermore, in recent decades the age at which gay people come out to their family had drastically declined (Dunlap 2016). Not all gay youth receive the celebration they deserve. Nonetheless, gay youth may be afforded greater acceptance, on average, because their vulnerability evokes more compassion, especially (thought not always) from their parents.

Another important reason that interpersonal connections have driven a unique decline in anti-gay attitudes is that being gay is largely an invisible trait and can be effectively concealed in 
the face of social pressure, though concealment can be forced and often has negative psychological and social consequences (Badgett \& King, 1997). A prejudiced straight person can therefore get to know a gay person and build a relationship with them without realizing they are gay. In addition, the concealability of a person's gay identity is associated with reduced anxiety around and improved quality of intergroup interactions (Forestier et al., 2020). The invisibility of outgroup status is far less likely for relationships that cross divisions of race and gender, since individuals' membership in these social categories is typically highly visible and difficult to conceal (Herek, 2016; Davies et al., 2011). Unlike anti-gay attitudes, then, racist attitudes can pre-empt the development of close interpersonal connections that initiate acceptance of marginalized people and collapse of negative attitudes. Of course, men and women are highly interdependent, and thus sexist men have always had plenty of interpersonal connections with women. Sexist attitudes do not pre-empt close interpersonal connections so much as distort them, by leading men to perceive the women in their lives--mothers, siblings, daughters, friends, partners--through a sexist lens from the outset of their relationships. Some men think that they have an obligation to protect women, but that the proper roles for women are to serve as faithful wives and mothers rather than any authoritative roles outside the home. Their sexism is often "benevolent" rather than "hostile." Research in intergroup contact theory suggests that the key difference is the relative invisibility of sexual orientation, especially compared with race and gender, allowing many people to develop close interpersonal connections with gay people despite latent anti-gay attitudes (Herek, 2016). So, the unfortunate fact that gay people were forced to conceal their sexuality was a precondition for progressive attitude change. If gay people had not been closeted, fewer close interpersonal connections would have been made. 
Being gay is largely an invisible trait in the sense that gay people can look like straight people. Sexual orientation can of course be signaled in observable ways, but this signaling is largely under an individual's control. Put another way, gay people can "pass" as straight. Invisibility and "straight-passing" may seem like the very same feature, but straight-passing is relevant in an additional way. Previous work suggests that bias is often easier for people to overcome when they share attributes, including superficial appearance (e.g., features like age and weight) (Charlesworth \& Banaji, 2019; Essien et al., 2020). Therefore, people may more easily rid themselves of their biases against others if they both at least look like they belong to the same group. Conversely, easily observable differences may amplify bias (Zebrowitz, 1996), either because appearances serve as automatic affective cues, or because people infer that individuals are intentionally signaling their membership in a different group (e.g., Krakauer \& Rose, 2002). The significance of straight-passing as such can also explain why anti-gay attitudes are not likely to have declined as much for gay people whose appearance and behavior do not conform to traditional values and expectations, as noted at the end of the previous section.

When two people are in a close relationship, it is common for each to experience positive affect toward the other and hold strong beliefs that they are good people (Kim et al., 2020; Fatfouta et al., 2018). This predisposition can overwhelm any negative information about someone's being gay. A similar dynamic is found in one-way relationships with celebrities, such as musicians, film and TV stars, and social media personalities, as well as people in positions of status or authority, such as politicians, teachers, and business leaders (e.g., Gabriel et al., 2018; Chung \& Cho, 2017). For example, consider a widely admired actor who has accumulated status while being closeted. When she reveals herself to be gay, even those fans with anti-gay attitudes may retain an overall positive orientation toward her. What matters are people's strong positive 
priors, whether they are built on experiences within close relationships or other interpersonal connections developed from afar. Social affect and prior beliefs can be similar across these different kinds of relationships and influence attitudes in similar ways (Kim et al., 2020).

Broadly speaking, anti-gay attitudes can be ameliorated via interpersonal connections in two different ways, which lie on a spectrum. At one extreme are individuals who have long been anti-gay, perhaps because they are older and were raised in deeply homophobic cultural environments (e.g., Baby Boomers and the Silent Generation). After discovering that a family member or friend or celebrity is gay, they may experience an "epiphany." This insight-based experience can destabilize otherwise resolute attitudes. At the other extreme are individuals who are still forming attitudes about sexual orientation and its ethical significance, often because they are younger and have not yet undergone anti-gay enculturation or extensive exposure to anti-gay ideology (e.g., Millennials and Generation Z). These people form relationships and imbibe more recent culture (that is more pro-gay than before), shaping attitude formation before anti-gay prejudice has had a chance to develop.

So far in this section, we have identified features of sexual identity that enable interpersonal connections between straight and gay people. Random distribution, invisibility, and straight-passing have each allowed a wide range of individuals to reform their attitudes toward the gay person (or gay people) in their lives. Initially, empathy and sympathy motivated people to reason about a close/admired person and care about the harm they experience. Beliefs may have changed first, while affective attitudes lagged behind (Campbell \& Kumar, 2012). Thus, in some cases, feelings of disgust and aversion can persist in the face of conflicting beliefs, evincing a dissociation between explicit and implicit attitudes (Nosek \& Smyth, 2007). For example, someone may claim to have no moral qualms about their daughter's sexual orientation 
but still exhibit automatic discomfort toward public expressions of her sexuality. Nonetheless, as we have argued so far, interpersonal connections initiate a local change in attitude toward close and admired others.

\subsection{General Changes}

A local change in attitudes toward particular gay people, whether partial or complete, does not suffice to alter general attitudes toward gay people as a whole and the issues that impact their lives. People have had to generalize. Many people have engaged in one or another form of “moral consistency reasoning” (Campbell \& Kumar, 2012). In this kind of moral reasoning, generally, people reason that their moral attitudes are inconsistent with one another. They revise their attitudes by "treating like cases alike," as philosophers sometimes put it, which can spur progressive attitude change (Kumar and Campbell, 2016, in press). Thus, people have reasoned that if there is nothing wrong with their daughter's sexual orientation, for example, there must be nothing wrong with the sexual orientation of so many strangers with whom they do not have interpersonal connections. Or they have reasoned that if they did not want their college friend to be treated with hostility and disgust, they could not treat strangers that way either. Another way of thinking about this psychological process is that people have experienced cognitive dissonance between their attitudes toward particular individuals and their attitudes toward gay people in general. Some of these people, though not all, have resolved this dissonance by changing their general anti-gay attitudes.

The first psychological mechanism in our theory is triggered when people have found themselves connected interpersonally with someone who is gay. Emotions like empathy and sympathy shine a spotlight on a gay family member or friend and motivate people to care about 
the various harms inflicted on them; for example, neurological evidence indicates that experiences of empathy are modulated by social closeness (Krienen et al., 2010; Fareri et al., 2012). Empathy may also provide people with the motivation to change their minds and thereby sustain the relationship. A motivated framework suggests that people feel empathy for socially close others even when it is painful to do so, in order to strengthen social bonds (Zaki, 2014). People even selectively discount ingroup members' negative behaviors, for the sake of maintaining close relationships (Park \& Young, 2020; Park et al., 2020; Kim et al., 2020). On the basis of such evidence, critics have argued that empathy or sympathy is irredeemably biased (Prinz, 2011; Bloom, 2017). However, this bias can be mitigated when people also engage in moral consistency reasoning or dissonance reduction. In some cases people endorse "special obligations" to kin; but in other cases people recognize a "general obligation" to kin and strangers alike (McManus et al., 2020). Thus, empathy and sympathy are valuable because they can act as a catalyst, initiating moral consistency reasoning that leads to generalization.

Importantly, however, a common strategy is available that can block moral consistency reasoning and prevent it from spurring progressive attitude change. Specifically, people often engage in "subtyping." That is, they treat their family member or friend as a special case, accepting that person but refusing to accept others. Or, when presented with a stereotype-inconsistent example, they maintain the previously held stereotype by deciding that the example is an exception to the general rule (Maurer et al., 1995; Richards \& Hewstone, 2001). For example, someone may insist that his gay daughter, whom he adores, is nothing like other people who are gay. He may think that his daughter's romantic behavior is based on love, while other people act on "deviant" sexual impulses. In addition, he may be willing to accept a minority of gay people who are similar in relevant ways to his daughter, perhaps those in chaste 
or monogamous relationships, or his subtype may have only a single member (his daughter).

Subtyping may be spontaneous or it may be actively pursued to avoid an uncomfortable generalization. In any case, subtyping can prevent moral consistency reasoning that would have led this father and others like him to generalize and develop more progressive attitudes.

Let us summarize so that we can more clearly see the problem and, next, identify a solution. Through sympathy and empathy born out of interpersonal connections, people have begun to care about the harm inflicted on their friend or family member. Next, through moral consistency reasoning they have generalized their concern to other gay people they do not know personally. Via these two steps, anti-gay attitudes have been eliminated or reduced. However, subtyping can block moral consistency reasoning by preventing people from treating like cases alike. That is, they can make special exceptions for their friend or family member and maintain their prejudice toward strangers. Subtyping can therefore obstruct the generalization of local moral insights. Next, we will argue that common ideas about sexual orientation inhibit subtyping and thus explain why interpersonal connections and consistency reasoning have driven a unique decline in anti-gay attitudes.

We propose that subtyping is less common when a person's family member or friend is gay, as compared with other social categories, because sexual orientation is perceived, perhaps naively, as being less complex and rooted in biology (rather than experience). This is why, in part, anti-gay attitudes have undergone a larger, faster, and broader decline, compared to other prejudices. To see this, let us contrast perceptions of gay people with perceptions of those who are politically conservative, another social category that is relatively invisible and somewhat widely distributed. Imagine a young, liberal person who discovers that her boss is a Republican. Despite her own liberal political orientation, she comes to accept him. However, she also 
generates excuses for his beliefs and behavior (like his voting record) by pointing to specific facets of his political orientation. For example, she might ignore his distasteful opinions about social justice and focus on his more reasonable beliefs about the importance of personal responsibility or the value of religious faith. Subtyping is viable here in part because political orientation is perceived to be a complex social category and therefore can be more easily decomposed into subtypes.

Sexual orientation, we argue, is perceived to be a less complex social category. First, whereas people recognize that there are a number of facets of political conservatism, being gay is perceived to have only a primary defining characteristic, i.e., same-sex sexual attraction and/or having sex with people of the same gender. Second, whereas conservatives are thought to experience varying degrees of oppression and privilege, gay people are thought to share common experiences of being harmed by anti-gay laws, norms, individuals, and institutions. These beliefs may well be mistaken. For example, people with positive attitudes toward "gay people" may reflect only on White, upper-class individuals whose behavior conforms to traditional values. They may be unaware of many other "subtypes" (consider the example of a gay Muslim immigrant in the US: xenophobia and the pathologizing of Muslim sexuality in the US (Puar, 2018) may render such a person invisible). Or they may even create exceptions for gay people who are, say, transgender or polyamorous, resisting a more general change in attitude and contributing to intersectional disadvantage. Nonetheless, because it is often relatively difficult to subtype gay people, friends and family members are more likely to generalize from close others who are gay to a broader social category. As a corollary, then, subtyping may be one reason that political divisions in America remain sharper than ever, and that political intergroup conflict is 
especially contentious (PEW, 2019; 2020), in spite of the fact that, like being gay, being conservative or liberal is also largely an invisible trait and relatively easy to conceal.

We have argued that many people have undergone a local change in attitudes by discovering that a family member or friend or celebrity is gay and then generalizing their attitude to strangers. One lingering puzzle, however, is why this process happened when it did. Why did interpersonal connections produce a decline in anti-gay attitudes over the last 50 years rather than earlier, say, in the first half of the 20th century, or rather than later, say, in the second half of the 21 st century? The solution to this puzzle requires distinguishing what was always true vs. what has only recently become true. A range of important cultural and political conditions were also necessary to generate the effect, and these conditions began to emerge only during the last 50 years or so. We will highlight three of the most important such conditions, but we are confident that others were also necessary.

First, the HIV/AIDS crisis erupted in the early 1980s. This introduced new stigmas against gay people, but it also forced many to be open to their friends and family. As a result, the psychology of interpersonal connections, as reviewed above, effected a change in attitudes (albeit only for those who had interpersonal connections with gay people). Evidence in support of this idea is that anti-gay attitudes actually exhibited a greater decline in U.S. states with higher rates of HIV/AIDS (Fernandez et al., 2019).

A second important condition was the development of gay subcultures in many urban centers, enabled by high levels of freedom and mobility in the U.S. starting in the late 1960s (Hanhardt, 2013). In these cities it was finally possible for gay people to be open about their identity, avoid prejudice, and find like-minded peers. Critically, many gay people retained ties to family members and friends outside their gay communities, which enabled those with 
interpersonal connections with gay people to change their minds. These subcultures would eventually expand and spread to other locations, including not just cities and towns but communities organized online. As a consequence, far more gay people were able to live openly than in the past, enough to produce a cascade in attitude change. Importantly, changes to the broader culture also fed back into psychology, through a kind of positive feedback loop (Kumar \& Campbell, in press). Put succinctly, the feedback loop is that communities that welcomed gay people made it easier for them to live openly, which changed the attitudes of close others, which changed the broader culture, which then made it easier, again, for gay people to live openly, and so on. This positive feedback loop helps explain why the decline of anti-gay attitudes was so large and fast.

A third possible condition, much more general, was the emergence of the civil rights movement and women's rights movements in the 1960s and 1970s. These movements were associated with intense political activism and heightened consciousness about socio-cultural restrictions. Arguably, they helped lead to the emergence of a more pluralistic and tolerant “counter-culture," which fostered greater acceptance of gay people and other oppressed groups. Thus, earlier movements toward social justice for Black people and women may have had far-reaching, secondary consequences.

Let us summarize our discussion of the first psychological mechanism identified by our theory. A wide range of people are likely to have an interpersonal connection with someone who is gay — more likely than someone from a racial/ethnic outgroup — because homosexuality is a hidden or otherwise concealable trait, associated with a "straight-passing" appearance, that is randomly distributed across the population. Emotions that sustain interpersonal relationships can prompt acceptance of gay family and friends. At one extreme, longstanding anti-gay attitudes 
among older people vanish, either slowly or suddenly. At the other extreme, incipient anti-gay attitudes among younger people never develop at all. The next step is for people to engage in moral consistency reasoning, treating like cases alike and generalizing their acceptance. Without an easily available basis on which to subtype, some people reason that there are no morally relevant differences between their gay friend or family member and other gay people, i.e., that prejudice against the former is also wrong when directed against the latter. The collective and cumulative result of all of these small-scale, interpersonal events is a large-scale, societal shift.

\section{Psychological Mechanism II: Social Category Classification}

We propose a second psychological mechanism that involves social category classification. People tend to "essentialize" social groups. That is, to a first approximation, they tend to believe that all members of a given social group share a hidden, genetic essence that explains the surface-level features they have in common. We will argue that this widely present and deep-seated psychological disposition helps explain the relatively large, rapid, and broad decline of anti-gay attitudes, in comparison with negative attitudes toward other marginalized groups including women and people of color. On the one hand, essentialism about sexual orientation tends to reduce anti-gay attitudes because it leads people to believe that individuals do not freely choose to be gay and lack the power to change their sexual orientation (i.e., "born this way" narratives). On the other hand, essentialism about race and gender tends to amplify racist and sexist attitudes because it leads people to discount the role of structural oppression in generating inequality and also to accept the inevitability of racial and gender differences. In the rest of this section, we will develop this explanation surrounding accessible counterfactuals across these 
different cases alongside a key difference in the moral status of the cases. We will begin with a review of work on psychological essentialism.

A large body of empirical work suggests that essentialism is a common stance in folk psychology (Gelman, 2003; Bastian \& Haslam, 2006; Levy et al., 2001; Dar-Nimrod \& Heine, 2011; Heine et al., 2017). From a very young age, people tend to believe that animals, people, and certain objects have hidden essences. These essences are regarded as discrete, immutable, biological, shared by all members within a relatively homogenous kind, and underlying other, surface-level traits they have in common. Important for the present theory, people are disposed to essentialize not just natural substances and biological taxa but also social categories. That is, those who essentialize tend to believe that all men or all Asian people, for example, share a hidden, immutable, and biological essence that can never be changed and that plays an important role in causing all men or all Asian people to act and appear the way they do. When it comes to animals and people, in contrast with inanimate objects, essentialism typically has a genetic aspect (Dar-Nimrod \& Heine, 2011; Heine et al., 2017), though not always (Heiphetz et al., 2017). That is, this research finds that the essence of a given biological and social category is often thought to lie in genes that are shared by all members.

It has been widely thought that gay people choose their sexual orientation. Indeed, some people who understand themselves to be straight may choose to be in a gay relationship. Increasingly, however, many people believe that whether a person is attracted to individuals of the same or opposite gender is fixed by a biological (genetic) essence (Haslam \& Levy, 2006). While some activists and critical theorists reject this idea, it is nonetheless common in popular culture. Many pro-gay cultural figures often repeat the slogan that gay people are "born this way." That gay people are coming out much earlier in their lives compared to previous 
generations (Dunlap 2016) may reinforce "born this way" narratives. These narratives, we believe, reflect a powerful psychological mechanism. Studies indicate that people who are essentialists about sexual orientation are more likely to have positive attitudes toward gay people and the issues that affect them (Heine et al., 2017). Manipulations of perceived etiology, by emphasizing genetic explanations for sexuality, increase support for LGB causes among American and European populations (Falomir-Pichastor \& Mugny, 2009; Frias-Navarro et al., 2015; Roberts et al., 2017). Perceptions of the increased immutability and naturalness of sexual orientation reduce perceptions of culpability and lead to less assignment of blame (Cheung \& Heine, 2015).

Interestingly, this pattern stands in contrast to perceptions of biological predispositions for body weight. People tend to discount the role of biology in body weight (preferring, instead, to explain body weight with reference to personal, controllable characteristics like diet or exercise), which may also explain why anti-fat bias has actually increased in the past two decades in spite of the fact that there is greater contact with self-defined fat people today (Charlesworth \& Banaji, 2019). In fact, recent work reveals that biological explanations reduce children's anti-fat bias, hinting at the power of essentialist attitudes for prejudice reduction during a time when both essentialism and explicit prejudice are at their peak (Carvalho, Peretz-Lange, \& Muentner, in press).

Notably, precisely characterizing the components of essentialism is an ongoing empirical project that has not yet achieved consensus (e.g., Heiphetz et al., 2017; Noyes \& Dunham, 2019, Dar-Nimrod \& Heine, 2011, and Haslam \& Levy, 2006). Here we focus on two distinct but related components of essentialism that both appear to reduce anti-gay bias: biology, as discussed above, and immutability (Heiphetz et al., 2017). That is, when people essentialize a group of 
people they tend to think that their traits and behavior are rooted in their biological (genetic) inheritance and also highly stable and not subject to change over time. In the context of essentialism about sexual orientation, people tend to think that being gay is both biologically (genetically) determined and something that cannot be changed. Of course, these two components are related. People may reason that being gay is immutable because it is biologically determined. We propose, however, that the two components have complementary but separable consequences for attitudes toward gay people. Our own ongoing experimental work tests these ideas, including whether gay men are essentialized differently from gay women.

In general, people have had a tendency to moralize being gay. Essentialism counteracts that tendency via two routes. First, people may reason that if being gay is biologically determined then it is not freely chosen. In general, people tend to believe that biological determinism preempts free choice and moral responsibility (Nahmias, 2011). Philosophers sometimes articulate the principle as follows: free choice and moral responsibility require the ability "to do otherwise" (Locke, 1690; Clarke, 2009). Thus, people have reasoned that, if your genes caused you to be gay, then being gay was not up to you, and you cannot be held morally responsible for being gay. There is no sense in blaming someone, much less loathing them, for something that they have no control over.

Second, people may reason pragmatically that if being gay is immutable then gay people must be accepted. This reasoning rests, likewise, on a more general principle. As philosophers put it, "ought implies can." More precisely, someone is morally obligated to do something only if it is possible for them to do it (Kant, 1781). Given the present state of research, it is not clear whether the general public believes ought implies can (Kurthy et al., 2017; cf. Chituc et al., 2016). However, what seems to be more clear is that "blame implies can" (Buckwalter and Turri, 
2015). Now, remember that essentialism entails that being gay is immutable. Thus, people have reasoned that if it is not possible for a gay person to change their sexual orientation, then they cannot be blamed for being gay, and one might as well accept them for who they are.

In the previous section we introduced a puzzle about timing: why did interpersonal connections cause a decline in anti-gay attitudes over the last 50 years rather than earlier or later? A similar puzzle arises in the context of social category classification: why did an essentialist stance come to be applied to gay people and cause a decline in anti-gay attitudes when it did? Our solution to this puzzle depends on the hypothesis that the two mechanisms are interrelated. As hinted previously, one reason that people have found it difficult to subtype gay people, failing to create exceptions that block generalization through moral consistency reasoning, is that they tend to see all gay people as having a shared biological essence and therefore members of a single social kind. Conversely, interpersonal connections also supported the mechanism of social category classification. As gay people formed communities in which they could live openly, more individuals lived open and candid lives, which, in turn, changed the attitudes of close others, changed the broader culture and (in a full circle) made it easier for gay people to live openly, creating a positive self-reinforcing cycle. Thus, we hypothesize that it is because gay people gained greater visibility as a relatively homogeneous or entitative group that straight people began to essentialize them. In addition, pro-gay activists and cultural figures have initiated an active push to essentialize gay identities--via "born this way" narratives and increased use of generic labels for gay people--which has led others to passively adopt an essentialist stance (Peretz-Lange \& Muentner, 2020; Rhodes et al., 2012). That gay people are coming out much earlier in their lives compared to previous generations (Dunlap 2016) may reinforce "born this way" narratives, especially it is less likely for people to think that children 
are coerced by a pro-gay "agenda." More youth are openly gay because of greater public acceptance. For the reasons given here, however, this is likely not just an outcome of but also a contributor to greater acceptance. All of the factors discussed above may be why essentialism was operant during the last 50 years, leading straight people to infer that sexual orientation is not freely chosen or mutable.

We have argued that the increasing prevalence of essentialism about sexual orientation can account for the decline in anti-gay attitudes. However, it is less clear why essentialism about sexual orientation should lead to a decline in anti-gay attitudes, whereas essentialism about gender and race has been shown to have the opposite impact in the case of sexism and racism, reinforcing anti-women and anti-Black attitudes. Indeed, past research suggests that essentialism about social categories is a broadly ethically regressive force. For example, studies find that essentialism is tied to negative attitudes toward Black people (Jayaratne et al., 2006; Mandalaywala et al., 2018), women (Brescoll and LaFrance 2004), Aboriginal people (Bastian \& Haslam, 2006), members of lower classes (Kraus \& Keltner, 2013), immigrants (Bastian \& Haslam, 2008; Zagefka et al., 2013), and criminals (Martin \& Heiphetz, in press). The puzzle of why essentialism tends to lead to more bias against some marginalized groups (e.g., gender and race) but less anti-gay bias is worth exploring in future empirical work. We present a speculative hypothesis below.

Our hypothesis involves both alternative or counterfactual explanations accessible across the cases alongside the moral status of the cases, i.e., people tend to moralize being gay in a way that they do not necessarily moralize being a woman or a person of color. For example, some people think it is wrong for men to have sex with other men. These people moralize being gay. This is different from thinking that disparities in outcomes are morally justified, such as when 
people think that women or Black people deserve to occupy subordinate roles. The key point is that homophobia and sexism/racism depend on different forms of moralization. Now, when it comes to sexual orientation, people believe that same-sex sexual attraction or behavior can be explained by either biology or free choice; essentialism leads people to explain same-sex sexual attraction in terms of biology and to discount free choice. Since the trait is thought to be due to a fixed essence and cannot be changed, blame is reduced and so is the motivation to change the behavior. (Note that this appears to be the case for body weight as well, as discussed above; people tend to think of body weight as a product of either biology or free choice. Most people would struggle to accept that the amount one eats is an essential aspect that cannot be controlled and, in that case, would blame people for their weight. But if the perspective is shifted to be about the baseline metabolic processes being uncontrollable, they might accept that this is essential and beyond control and reduce blame.) When it comes to gender and race, people believe that group differences can be explained by either biology or social structure; essentialism leads people to underplay structural sexism and racism. For Black people and women, there is not a single, specific trait or behavior that is essentialized. But disparities in outcomes are attributed to essential differences in identity. People may not blame Black people or women for those different outcomes, but there is also no motivation to rectify the disparate outcomes. Thus, essentialism itself may or may not be the causal factor in initially determining attitudes and prejudice, but it can be used as a way of justifying existing hierarchies and sustaining belief in their acceptability (Haslam \& Whelan, 2008). Essentialist attributions may be a way of ignoring structural explanations for group differences, especially in social outcomes (Peretz-Lange \& Muentner, 2019; Peretz-Lange \& Muentner, 2020). Thus, in the case of sexual orientation, essentialist beliefs might result in removing culpability for being gay, but in the case of race, 
essentialist beliefs might function as legitimizing ideologies for enforcing or allowing the subordination of Black people (Jayaratne et al., 2006).

We can illustrate this idea with some examples. Black people are underrepresented in academia, both as professors and university students (Supiano, 2015; Ashkenas, Park, \& Pearce, 2017). Some people argue that this disparity exists because Black people are biologically different from White people and other racial groups. Essentialism thus leads people to discount the role of systemic racism in generating educational disparities between Whites and Blacks. Parallel ideas apply to women. Many STEM fields also have a disproportionately low number of female full professors (Charlesworth \& Banaji, 2019). Some academics argue that the disparity exists because women are biologically different from men. On average, it is alleged, women have inferior mathematical abilities at least along some dimensions (Summers, 2005; Pinker, 2005), or they have a stronger interest in people and a weaker interest in objects and abstract ideas (e.g., Damore, 2017). Insofar as people believe this hypothesis about the biological differences between men and women, they are likely to discount the role of systemic sexism in generating the group disparity. For race and gender, biological explanations contained within essentialism lead people to underplay structural causes of racial and gender inequality. In the case of anti-gay bias, however, biological explanations replace free choice, mitigating attributions of responsibility and driving acceptance. Again, inherent in this proposed solution to the puzzle is another key difference: people tend to moralize being gay (e.g., the question of culpability is on the table) in a way that people do not necessarily moralize gender or race. Exactly why people moralize being gay in the first place is a separate puzzle we identify for further empirical investigation. 
Let us summarize our discussion of the second psychological mechanism described by our explanatory theory. In section 3, recall, we argued that people develop positive attitudes toward particular individuals and then modify their opinion about homosexuality in general. In this section our model depicts attitude change unfolding in the opposite direction. A general attitude toward homosexuality occurs first and results in attitude change toward individuals. People have tended to essentialize social categories, more recently including sexual orientation. Thus, people have come to believe that women, racial minorities, and gay people are "born that way," as a result of a hidden, immutable, genetic essence. This stance has had a number of consequences, but several are important for the present theory. First of all, people have tended to infer that gay people are not morally responsible for their sexual orientation and that they cannot become straight in the future, which implies that there is little choice but to accept them for who they are. So, essentialism has led many people to abandon anti-gay attitudes. However, essentialism has not had the same effect on racist and sexist attitudes. From an essentializing stance, people have tended to infer that racial and gender inequality is the result of immutable, biological differences rather than racism and sexism, respectively. Essentialism has justified and reinforced racist and sexist attitudes. Thus, essentialism interacts with bias differently depending on the alternative explanation accessible for the bias: in the case of sexual orientation (and body weight), the alternative to essentialism is free choice, but in the case of inequalities due to race and gender (and other forms of marginalization), the alternative to essentialism is structural racism and sexism. In brief, alongside interpersonal connections, essentialist classification of the social category of being gay has helped bring about a relatively large, rapid, and broad decline of anti-gay attitudes. 


\section{Extensions to Other Societies and to Other Marginalized Groups}

We have developed a detailed psychological explanation for how two mechanisms have fostered a large, rapid, and broad decline of anti-gay attitudes. One reason for pursuing an explanatory theory about anti-gay attitude change, aside from its inherent worth, is that it can offer a basis for predicting how prejudiced attitudes might decline in the future. From an ethical and policy perspective, furthermore, the theory can also be used to identify conditions that can engender further progressive attitude change. In this section, we will extend the theory to three domains: from American history to its future (section 5.1); from America to other societies that have not yet experienced a similar decline (section 5.2); and from gay people to other marginalized groups such as transgender people (section 5.3).

\subsection{The Future of Anti-Gay Attitudes in America}

Our explanatory theory is intended to explain a decline in attitudes that began, roughly, in the late 1960 s and continues into the present day. An important question is whether the decline will continue and what shape it will take. As mentioned in section 2, younger generations have more positive attitudes toward gay people. It seems unlikely that the children of Millenials and Generation $\mathrm{Z}$ will revert to anti-gay positions. That being said, we hypothesize that both mechanisms will continue to erode anti-gay attitudes, but that future attitude change will depend on the persistence of allied institutional changes of the sort discussed briefly in section 2 .

Alongside progressive changes in attitude and behavior, Americans have also reformed political, legal, religious, military, and medical institutions. Further reform would create an even more welcoming environment, making it easier for gay people to live open and candid lives, which would likely facilitate further attitude change through both of our proposed mechanisms. First, as 
more gay people live openly, more straight people are likely to encounter gay people and essentialize the social category of being gay. Many of these people will draw the inference that sexual orientation is not under a person's control and cannot be changed. Second, and more obviously, as more gay people are open about their sexual identity, a greater number of straight people will discover that close or admired others are gay. Thus, empathy and sympathy will continue to act as a moral wedge that initiates a series of local and general changes in attitude. A particularly important locus of reform is in media institutions, including social media. Anti-gay attitudes are likely to continue declining as a result of increased diversity, such that more gay men and women are represented in film and television and given prominence on emerging social media platforms. In both cases, the consequence is greater visibility that encourages interpersonal connections and essentialist classification.

However, we speculate that both of the mechanisms identified in this article may eventually bump up against two counteracting forces. In particular, essentialism about sexual orientation may rest on errors that will increasingly be brought to light. As some biologists and critical theorists argue, it may simply be false that gay people are "born that way." Essentialism may be true in physics, but its application to social categories is far more tenuous. Even if sexual orientation is influenced by biology, it is also likely to be influenced by culture; it may be a "bio-cultural" trait. As more people discover this (putative) fact, they may abandon their essentialist stance toward sexual orientation, and therefore may refrain from inferring that gay people have no free choice over their sexuality. They may also discover that sexuality is fluid and plastic, and therefore not immutable in a way that preempts (moral) responsibility.

A second counteracting force on the continuing decline on anti-gay attitudes in America is related to the first. Remember that interpersonal connections can initiate a cascade of further 
changes in attitude. A general change in attitudes unfolds when people reason that if discrimination against a close other is wrong, then so is discrimination on the same basis against strangers. As we argued in section 3.2, moral consistency reasoning is likely to be disrupted when people are more easily able to subtype. Thus, if people discover that essentialism is false because there are multiple pathways toward gay identity, as discussed above, they may be inclined to abandon negative attitudes toward some subtypes but not others. Furthermore, as gay people become increasingly visible in American society, more people may become aware of diversity within gay communities, in particular, gay individuals who are polyamorous or transgender, or who otherwise do not exhibit traditional identities and lifestyles. A consequence of an increase in the perceived heterogeneity and reduced entitativity within this social category is that people may be more likely to engage in subtyping, that is, revise anti-gay attitudes about some individuals or subtypes but not others. Relatedly, straight people's attitudes may undergo a backlash as they discover more gay people who do not fit the mainstream mold.

One possible solution is for Americans to discover more enlightened reasons for accepting gay people. First, people should ideally be able to reason about the unacceptability of anti-gay discrimination without needing to have an interpersonal connection with someone who is gay. Put simply, it is wrong for someone to face discrimination whether or not they are your friend or family member. Second, adults should have the freedom to pursue romantic relationships with whomever they desire; whether or not their desires are essential to their identity (or biological or immutable) is immaterial. One day, more Americans might internalize arguments against anti-gay prejudice that are not catalyzed by gay close others, and that do not assume that being gay is a genetic trait, for example. Interpersonal connections and essentialism 
might eventually become a ladder that Americans can kick away after they have already climbed it.

\subsection{Anti-Gay Attitudes in Other Societies}

In this article we have focused on the decline of anti-gay attitudes in the U.S. The reason is not that social change in America is more important than social change in other countries; rather, much of the data that we draw upon -- including polling data and empirical studies of bias -- are derived exclusively from research on American populations. Nonetheless, it is reasonable to infer that the trends we documented in section 2 and the psychological mechanisms we identified in section 3 and section 4 are also present in other countries that are culturally similar to the U.S., including Canada, Australia, New Zealand, Great Britain, and other countries in Western Europe. Attitude change in the U.S. has lagged behind many of these countries. For example, in The Netherlands, the first country to legalize same sex marriage, in 2001 , one survey finds that $92 \%$ of the Dutch population thinks that homosexuality should be accepted by society (Pew, 2020). It is possible that the reason anti-gay attitudes declined earlier in The Netherlands, compared to the U.S. and other countries, is that visible gay communities emerged there earlier, catalyzing interpersonal connections and essentialist reasoning, though further research is needed to support this idea.

Notably, all of the countries mentioned above are WEIRD, that is, western, educated, industrialized, rich, and democratic (Henrich et al., 2010). Here, we ask about non-WEIRD countries. First of all, it is somewhat misleading to group all non-WEIRD countries together into a single category; there is enormous diversity among them. Consider again one of our proxies for the decline of anti-gay attitudes, that is, the shifting proportion of people who favor or oppose 
same-sex marriage. According to Pew surveys of global opinion, several non-Western countries have exhibited a similarly large and rapid shift in attitude, including Mexico, Argentina, Japan, South Korea, India, South Africa (Pew, 2020). In fact, Argentina and South Africa legalized same-sex marriage years before the US. By contrast, acceptance of same-sex marriage is moderate, with populations being roughly split, in most countries within Eastern and Central Europe (excluding Russia and Ukraine, where acceptance is low). Acceptance in most countries in sub-Saharan Africa and the Middle-East is low (excluding South Africa and Israel, where acceptance is high). Within Asian-Pacific countries, there is a great deal of variation (e.g., 73\% of people in the Philippines and only $9 \%$ of people in Indonesia).

Famously, there is a great deal of psychological variation more generally between people who were raised in WEIRD vs. non-WEIRD countries (Henrich et al., 2010). However, we are not aware of evidence indicating that people from non-WEIRD countries are less likely to undergo processes implicated in our proposed psychological mechanisms. And, for example, children tend to be even more essentialist than adults, which suggests low cultural variation (Wright, 2012; Heiphetz \& Young, 2017; Heiphetz et al., 2017; Heiphetz et al., 2018). More likely, the differences are due to cultural and political conditions that we have proposed are also necessary to drive the decline in anti-gay attitudes. In particular, some non-WEIRD countries do not enjoy the same freedom and mobility that enable communities of gay people to arise and, more recently, to express themselves in media. In addition, political forces in these countries have not mobilized to engender reform of social institutions. In some cases, this may be due in part to the colonialist imposition of Western values that disrupted pre-existing acceptance (M'Baye, 2013; Hoad, 2007). Further research is needed to shed light on why interpersonal connections and social category classification have not caused a similar decline in anti-gay 
attitudes around the world. We should expect divergent explanations across different countries and regions. We should also be aware that other cultures possess different gender and sexuality categories that do not line up with those in WEIRD countries that our theory has relied on (Parker, 2009).

\subsection{Anti-Trans Attitudes}

We have been careful to specify that the prejudiced attitudes that have declined are largely targeted toward gay men and women rather than the broader LGBTQ community as such. That is, there has not yet been a similar decline in prejudiced attitudes toward bisexual, transgender, and queer people, more broadly. It is important to examine why. One likely reason has to do with intersectionality, and specifically with "respectability politics" (Strolovitch \& Crowder, 2018). In the case of many progressive social changes, initial benefits are accorded to only a proper subset within a given marginalized group. For example, first and second wave feminism were mobilized primarily to advance the rights of White, upper-class women. Feminists rallied to advance the ability of women to join the workforce; the problem for Black and Indigenous women was not that they could not work outside the home but that they were allowed to fulfill only subordinate roles where they risked exposure to physical violence. Similarly, early progress within the movement toward LGBTQ equality benefited (some) gay men and women, while sidelining the interests of bisexual, transgender, and queer people who experienced greater marginalization (Finley, 2020). The latter groups enjoyed even less "respectability," i.e., their appearance and behavior conformed less with traditional values. This is analogous to other social changes. For example, in the 20th century, Polish, Irish, Italian, and other immigrant groups gained the status of Whiteness, while Latinx and Asian people continued to be othered (Roediger, 2005). Another 
factor is that, compared to gay people, a smaller proportion of the population is trans (The Williams Institute, 2016). Therefore, even under the assumption that these identities are distributed diffusely, a fewer number of straight people have been in a position to discover that a friend or family member is trans.

So far, progressive changes that improve the lives of trans people have been slow to accumulate. Anti-trans attitudes may now be at a level that compares to anti-gay attitudes several decades ago. Implicit and explicit anti-trans attitudes not only remain high but are also correlated with transphobia and support for anti-trans policies (Axt et al., 2020). In fact, it is possible that acceptance of gay people is partly a result of the public emergence of trans people and others who are subject to greater relative stigma, which has modified the anchors on rating scales. Optimistically, however, we hypothesize that both of our proposed psychological mechanisms have the ability to foster a decline in anti-trans attitudes. Pro-LGBTQ activists gain similar traction by arguing that trans people are "born that way." Seminal work by Kristina Olson and colleagues has revealed that children as young as 3 years old who are living as a gender different from their sex assigned at birth strongly identify with their current gender and display gender-typed preferences and behaviors in a way that is indistinguishable from their cisgender peers (Gülgöz et al., 2019; Olson et al., 2015). In addition, transgender children are as likely as cisgender children to essentialize gender, despite their social experiences of gender transition (Gülgöz et al., 2019). Trans children's gender identity does not vary as a factor of how long they have been out as trans, and, for children who eventually transition, their gender identity does not significantly differ before and after transition (Gülgöz et al., 2019; Rae et al., 2019). Given the robustness of gender identity so early in development, cisgender people may be in a position to infer that gender identity is not a matter of free choice and moral responsibility, and also not 
something that can be changed. By contrast, and, somewhat more pessimistically, we hypothesize that it is more difficult for people to take an essentialist stance toward bisexual individuals, since non-discrete (non-binary) expressions of sexuality and gender conflict with components of essentialism. In addition, as mentioned in section 5.1, essentialism about all of these categories may become more tenuous as people discover the cultural influences on sexuality and gender and their fluidity.

In general, psychological changes unfold in concert with political and cultural changes. This is no less true for attitudes toward trans people. Thus, we expect that the reform of anti-trans attitudes will also require the reform of social institutions, especially in the face of backlash from people who think the movement is going too far. If medical, political, and religious institutions can be made more welcoming to trans people, then a greater number of trans people would feel safe to live openly and candidly. This would increase the number of cisgender people who discover that a friend or family member is trans. Some of these people could be expected to revise their attitudes toward the trans people in their lives, and through moral consistency reasoning, trans people who are strangers. As with declining anti-gay attitudes, diversity in traditional and social media has the potential to act as a powerful catalyst (Kumar \& Campbell, in press), for example, as prominent celebrities announce their transgender identity and enjoy relatively warm public reception.

\section{Conclusion}

In this article, we have proposed a psychological account for why anti-gay attitudes (with some important exceptions) have declined in the U.S. over the course of several decades, in concert with other progressive changes related to the behavior of straight people and institutional 
structure. In section 2 we argued that this phenomenon is unique in that, compared to other negative attitudes toward marginalized groups, such as women and people of color, the decline in anti-gay attitudes has been larger, faster, and broader. After describing the phenomenon, we developed an explanatory theory. We explained why anti-gay attitudes have exhibited a unique decline via two related psychological mechanisms. In section 3 we argued that people have undergone a local change in attitudes within interpersonal relationships before generalizing their attitude change through moral consistency reasoning. In section 4 we argued that psychological essentialism (including "born that way" narratives) has led people to withdraw blame from gay people and accept them for who they are. In section 5 we developed hypotheses about whether, and under what conditions, our two mechanisms might drive further progressive changes in attitudes in other countries and toward other marginalized groups, including especially trans people. Of course, more research is needed particularly at the intersection of psychology and politics and culture, and much more moral progress needs to be made on multiple fronts. Continued investigation of the phenomenon can launch future progressive change and, more generally, inform the psychology of moral progress.

Acknowledgments: The authors thank Stefano Anzellotti, Michael Brownstein, Richmond Campbell, Tessa Charlesworth, Tony Chen, Fiery Cushman, Isaac Handley-Miner, Skylar Hawthorne, Josh Hirschfeld-Kroen, Kevin Jiang, Minjae Kim, Gordon Kraft-Todd, Casey Lewry, Michael Manalili, Julia Marshall, Justin Martin, Joel Martinez, Joshua May, Ryan McManus, BoKyung Park, Rebecca Peretz-Lange, Peter Railton, and Aja Watkins for thoughtful feedback and discussion, and the John Templeton Foundation and the National Science Foundation for their support. 


\section{References}

Ashkenas, J., Park, H., \& Pearce, A. (2017). Even with affirmative action, Blacks and Hispanics are more underrepresented at top colleges than 35 years ago. The New York Times Company. Retrieved December 18, 2020, from https://www.nytimes.com/interactive/2017/08/24/us/affirmative-action.html.

Anderson, E. (2010). The Imperative of Integration. Princeton University Press.

Axt, J., Conway, M., Westgate, E., \& Buttrick, N. (2020). Implicit transgender attitudes independently predict beliefs about gender and transgender people. PsyArXiv. https://doi.org/10.31234/osf.io/wjts3

Bastian, B., \& Haslam, N. (2006). Psychological essentialism and stereotype endorsement. Journal of Experimental Social Psychology, 42(2), 228-235. https://doi.org/10.1016/i.jesp.2005.03.003

Bastian, B., \& Haslam, N. (2008). Immigration from the perspective of hosts and immigrants: Roles of psychological essentialism and social identity. Asian Journal of Social Psychology, 11(2), 127-140. https://doi.org/10.1111/j.1467-839X.2008.00250.x

Bloom, P. (2017). Empathy and Its Discontents. Trends in Cognitive Sciences, 21(1), 24-31. https://doi.org/10.1016/j.tics.2016.11.004

Brescoll, V., \& LaFrance, M. (2004). The Correlates and Consequences of Newspaper Reports of Research on Sex Differences. Psychological Science, 15(8), 515-520. https://doi.org/10.1111/j.0956-7976.2004.00712.x

Bronfenbrenner, U. (1992). Ecological systems theory. In Six theories of child development: Revised formulations and current issues (pp. 187-249). Jessica Kingsley Publishers. 
Buckwalter, W., \& Turri, J. (2015). Inability and Obligation in Moral Judgment. PLOS ONE, 10(8), e0136589. https://doi.org/10.1371/journal.pone.0136589

Campbell, R., \& Kumar, V. (2012). Moral Reasoning on the Ground. Ethics, 122(2), 273-312. https://doi.org/10.1086/663980

Carvalho, K., Peretz-Lange, R., Muentner, P. (in press). Causal explanations for body size impact children's social preferences.

CBS News. (2020). CBS News Poll. Retrieved December 18, 2020, from https://www.cbsnews.com/news/supreme-court-opinion-poll-cbs-news/.

Charlesworth, T. E. S., \& Banaji, M. R. (2019a). Patterns of Implicit and Explicit Attitudes: I. Long-Term Change and Stability From 2007 to 2016. Psychological Science, 30(2), 174-192. https://doi.org/10.1177/0956797618813087

Charlesworth, T. E. S., \& Banaji, M. R. (2019b). Gender in Science, Technology, Engineering, and Mathematics: Issues, Causes, Solutions. The Journal of Neuroscience, 39(37), 7228-7243. https://doi.org/10.1523/JNEUROSCI.0475-18.2019

Charlesworth, T.E.S., \& Banaji, M.R. (in press). Patterns of Implicit and Explicit Attitudes II. Long-term change and stability, regardless of group membership.

Chaves, M. A. (2002). National Congregations Study - 1998, 2006, and 2012 [Cumulative File]: Version 3 [Data set]. ICPSR - Interuniversity Consortium for Political and Social Research. https://doi.org/10.3886/ICPSR03471.V3

Cheung, B. Y., \& Heine, S. J. (2015). The Double-Edged Sword of Genetic Accounts of Criminality: Causal Attributions From Genetic Ascriptions Affect Legal Decision Making. Personality and Social Psychology Bulletin, 41(12), 1723-1738. https://doi.org/10.1177/0146167215610520 
Chituc, V., Henne, P., Sinnott-Armstrong, W., \& De Brigard, F. (2016). Blame, not ability, impacts moral "ought” judgments for impossible actions: Toward an empirical refutation of "ought” implies “can.” Cognition, 150, 20-25. https://doi.org/10.1016/j.cognition.2016.01.013

Chung, S., \& Cho, H. (2017). Fostering parasocial relationships with celebrities on social media: Implications for celebrity endorsement. Psychology \& Marketing, 34(4), 481-495.

Clarke, R. (2009). Dispositions, Abilities to Act, and Free Will: The New Dispositionalism. Mind, 118(470), 323-351. https://doi.org/10.1093/mind/fzp034.

Cyrus, K. (2017). Multiple minorities as multiply marginalized: Applying the minority stress theory to LGBTQ people of color. Journal of Gay \& Lesbian Mental Health, 21(3), 194-202.

Damore, J. (2017). Google’s Ideological Echo Chamber. https://assets.documentcloud.org/documents/3914586/Googles-Ideological-Echo-Cham ber.pdf.

Dar-Nimrod, I., \& Heine, S. J. (2011). Genetic essentialism: On the deceptive determinism of DNA. Psychological Bulletin, 137(5), 800-818. https://doi.org/10.1037/a0021860

Davies, K., Tropp, L. R., Aron, A., Pettigrew, T. F., \& Wright, S. C. (2011). Cross-Group Friendships and Intergroup Attitudes: A Meta-Analytic Review. Personality and Social Psychology Review, 15(4), 332-351. https://doi.org/10.1177/1088868311411103

Dovidio, J., Love, A., Schellhaas, F., \& Hewstone, M. (2017). Reducing intergroup bias through intergroup contact: Twenty years of progress and future directions. Group Processes \& Intergroup Relations, 20, 136843021771205.

https://doi.org/10.1177/1368430217712052 
Drescher, J. (2015). Out of DSM: Depathologizing Homosexuality. Behavioral Sciences, 5(4), 565-575. https://doi.org/10.3390/bs5040565

Dunlap, A. (2016). Changes in coming out milestones across five age cohorts. Journal of Gay \& Lesbian Social Services, 28(1), 20-38.

Essien, I., Calanchini, J., \& Degner, J. (2020). Moderators of intergroup evaluation in disadvantaged groups: A comprehensive test of predictions from system justification theory. Journal of Personality and Social Psychology, No Pagination Specified-No Pagination Specified. https://doi.org/10.1037/pspi0000302

Falomir-Pichastor, J. M., \& Mugny, G. (2009). “I'm not gay. . . I'm a real man!”: Heterosexual Men’s Gender Self-Esteem and Sexual Prejudice. Personality and Social Psychology Bulletin, 35(9), 1233-1243. https://doi.org/10.1177/0146167209338072

Fareri, D. S., Niznikiewicz, M. A., Lee, V. K., \& Delgado, M. R. (2012). Social Network Modulation of Reward-Related Signals. Journal of Neuroscience, 32(26), 9045-9052. https://doi.org/10.1523/JNEUROSCI.0610-12.2012

Fatfouta, R., Meshi, D., Merkl, A., \& Heekeren, H. R. (2018). Accepting unfairness by a significant other is associated with reduced connectivity between medial prefrontal and dorsal anterior cingulate cortex. Social Neuroscience, 13(1), 61-73. https://doi.org/10.1080/17470919.2016.1252795

Fernández, R., Parsa, S., \& Viarengo, M. (2019). Coming out in America: AIDS, Politics, and Cultural Change (No. w25697; p. w25697). National Bureau of Economic Research. $\underline{\text { https://doi.org/10.3386/w25697 }}$

Finley, M. (2020). Respectability Politics and the Rights of Queer and Transgender People: Critiquing an Obsolete System in the 21st Century. POLITICUS, 29. 
Forestier, J. M. L., Page-Gould, E., Lai, C. K., \& Chasteen, A. L. (2020). Concealability beliefs facilitate navigating intergroup contexts. European Journal of Social Psychology, 50(6), 1210-1226. https://doi.org/10.1002/ejsp.2681

Frias-Navarro, D., Monterde-i-Bort, H., Pascual-Soler, M., \& Badenes-Ribera, L. (2015).

Etiology of Homosexuality and Attitudes Toward Same-Sex Parenting: A Randomized Study. The Journal of Sex Research, 52(2), 151-161.

https://doi.org/10.1080/00224499.2013.802757

Gabriel, S., Paravati, E., Green, M. C., \& Flomsbee, J. (2018). From apprentice to president: The role of parasocial connection in the election of Donald Trump. Social Psychological and Personality Science, 9(3), 299-307.

Gallup. (2014). Values and Beliefs Survey, [Data set]. Retrieved December 18, 2020, from https://news.gallup.com/poll/170801/americans-say-sex-couples-entitled-adopt.aspx.

Gallup. (2017). Values and Beliefs Survey, [Data set]. Retrieved December 18, 2020, from https://news.gallup.com/poll/234866/two-three-americans-support-sex-marriage.aspx.

Gelman, S. A., \& Gelman, F. G. L. H. P. of P. S. A. (2003). The Essential Child: Origins of Essentialism in Everyday Thought. Oxford University Press.

Gibson, P. (1989). Gay male and lesbian youth suicide. Prevention and Intervention in Youth Suicide (Report to the Secretary's Task Force on Youth Suicide, Vol. 3). https://ci.nii.ac.jp/naid/10026901423/

GLAAD. (2019). Where we are on tv: GLAAD's annual report on LGBTQ inclusion. Retrieved from https://www.glaad.org/whereweareontv19.

GLAAD. (2020). Where we are on tv: GLAAD's annual report on LGBTQ inclusion. Retrieved from https://www.glaad.org/whereweareontv20. 
Gray, K., Young, L., \& Waytz, A. (2012). Mind Perception Is the Essence of Morality.

Psychological Inquiry, 23(2), 101-124. https://doi.org/10.1080/1047840X.2012.651387

Greenwald, A. G., McGhee, D. E., \& Schwartz, J. L. K. (1998). Measuring individual differences in implicit cognition: The implicit association test. Journal of Personality and Social Psychology, 74(6), 1464-1480. https://doi.org/10.1037/0022-3514.74.6.1464

Gülgöz, S., DeMeules, M., Gelman, S. A., \& Olson, K. R. (2019). Gender essentialism in transgender and cisgender children. PLOS ONE, 14(11), e0224321. https://doi.org/10.1371/journal.pone.0224321

Gülgöz, S., Glazier, J. J., Enright, E. A., Alonso, D. J., Durwood, L. J., Fast, A. A., Lowe, R., Ji, C., Heer, J., Martin, C. L., \& Olson, K. R. (2019). Similarity in transgender and cisgender children's gender development. Proceedings of the National Academy of Sciences, 116(49), 24480-24485. https://doi.org/10.1073/pnas.1909367116

Hanhardt, C. B. (2013). Safe Space: Gay Neighborhood History and the Politics of Violence. Duke University Press.

Haslam, N., \& Levy, S. R. (2006). Essentialist Beliefs About Homosexuality: Structure and Implications for Prejudice. Personality and Social Psychology Bulletin, 32(4), 471-485. https://doi.org/10.1177/0146167205276516

Haslam, N., \& Whelan, J. (2008). Human Natures: Psychological Essentialism in Thinking about Differences between People. Social and Personality Psychology Compass, 2(3), 1297-1312. https://doi.org/10.1111/j.1751-9004.2008.00112.x

Heine, S. J., Dar-Nimrod, I., Cheung, B. Y., \& Proulx, T. (2017). Chapter Three - Essentially Biased: Why People Are Fatalistic About Genes. In J. M. Olson (Ed.), Advances in 
Experimental Social Psychology (Vol. 55, pp. 137-192). Academic Press.

https://doi.org/10.1016/bs.aesp.2016.10.003

Heiphetz, L., Gelman, S. A., \& Young, L. L. (2017). The perceived stability and biological basis of religious beliefs, factual beliefs, and opinions. Journal of Experimental Child Psychology, 156, 82-98. https://doi.org/10.1016/j.jecp.2016.11.015

Heiphetz, L., Strohminger, N., Gelman, S. A., \& Young, L. L. (2018). Who am I? The role of moral beliefs in children's and adults' understanding of identity. Journal of Experimental Social Psychology, 78, 210-219.

https://doi.org/10.1016/i.jesp.2018.03.007

Heiphetz, L., \& Young, L. L. (2017). Can only one person be right? The development of objectivism and social preferences regarding widely shared and controversial moral beliefs. Cognition, 167, 78-90. https://doi.org/10.1016/i.cognition.2016.05.014

Henrich, J., Heine, S. J., \& Norenzayan, A. (2010). The weirdest people in the world? Behavioral and Brain Sciences, 33(2-3), 61-83. https://doi.org/10.1017/S0140525X0999152X

Herek, G. M. (2016). The social psychology of sexual prejudice. In Handbook of prejudice, stereotyping, and discrimination, 2nd ed (pp. 355-384). Psychology Press.

Herek, G. M., \& Capitanio, J. P. (1996). "Some of My Best Friends” Intergroup Contact, Concealable Stigma, and Heterosexuals' Attitudes Toward Gay Men and Lesbians. Personality and Social Psychology Bulletin, 22(4), 412-424.

$\underline{\text { https://doi.org/10.1177/0146167296224007 }}$ 
Herek, G. M., \& Glunt, E. K. (1993). Interpersonal Contact and Heterosexuals’ Attitudes toward Gay Men: Results from a National Survey. The Journal of Sex Research, 30(3), 239-244.

Hoad, N. W. (2007). African Intimacies: Race, Homosexuality, And Globalization. U of Minnesota Press.

Jayaratne, T. E., Ybarra, O., Sheldon, J. P., Brown, T. N., Feldbaum, M., Pfeffer, C. A., \& Petty, E. M. (2006). White Americans' Genetic Lay Theories of Race Differences and Sexual Orientation: Their Relationship with Prejudice toward Blacks, and Gay Men and Lesbians. Group Processes \& Intergroup Relations, 9(1), 77-94. https://doi.org/10.1177/1368430206059863

Jellison, W. A., McConnell, A. R., \& Gabriel, S. (2004). Implicit and Explicit Measures of Sexual Orientation Attitudes: In Group Preferences and Related Behaviors and Beliefs among Gay and Straight Men. Personality and Social Psychology Bulletin, 30(5), 629-642. https://doi.org/10.1177/0146167203262076

Kant, I. (1781). Critique of pure reason. Modern Classical Philosophers, Cambridge, MA: Houghton Mifflin, 370-456.

Kim, M., Park, B., \& Young, L. (2020). The Psychology of Motivated versus Rational Impression Updating. Trends in Cognitive Sciences, 24(2), 101-111. https://doi.org/10.1016/i.tics.2019.12.001

Kraus, M. W., \& Keltner, D. (2013). Social class rank, essentialism, and punitive judgment. Journal of Personality and Social Psychology, 105(2), 247-261. https://doi.org/10.1037/a0032895 
Krakauer, I. D., \& Rose, S. M. (2002). The impact of group membership on lesbians' physical appearance. Journal of Lesbian Studies, 6(1), 31-43.

Krienen, F. M., Tu, P.-C., \& Buckner, R. L. (2010). Clan Mentality: Evidence That the Medial Prefrontal Cortex Responds to Close Others. Journal of Neuroscience, 30(41), 13906-13915. https://doi.org/10.1523/JNEUROSCI.2180-10.2010

Kumar, V. \& Campbell, R. (in press). A Better Ape: The Evolution of The Moral Mind and How it Made Us Human. Oxford University Press.

Kunst, J. R., Onyeador, I. N., \& Dovidio, J. F. (2019). Knowledge About Individuals’ Interracial Friendships is Systematically Associated with Mental Representations of Race, Traits, and Group Solidarity. PsyArXiv. https://doi.org/10.31234/osf.io/hgwr3

Kurthy, M., Lawford-Smith, H., \& Sousa, P. (2017). Does ought imply can? PLOS ONE, 12(4), e0175206. https://doi.org/10.1371/journal.pone.0175206

Levy, S. R., Plaks, J. E., Hong, Y., Chiu, C., \& Dweck, C. S. (2001). Static Versus Dynamic Theories and the Perception of Groups: Different Routes to Different Destinations. Personality and Social Psychology Review, 5(2), 156-168. https://doi.org/10.1207/S15327957PSPR0502_6

Lewis, G. B. (2011). The Friends and Family Plan: Contact with Gays and Support for Gay Rights. Policy Studies Journal, 39(2), 217-238. https://doi.org/10.1111/j.1541-0072.2011.00405.x

Locke, J. (1690). Second Treatise of Government. Ed. CB Macpherson. Indianapolis: Hackett. M'Baye, B. (2013). The origins of Senegalese homophobia: Discourses on homosexuals and transgender people in colonial and postcolonial Senegal. African Studies Review, 109-128. 
MacInnis, C. C., Page-Gould, E., \& Hodson, G. (2017). Multilevel Intergroup Contact and Antigay Prejudice (Explicit and Implicit): Evidence of Contextual Contact Benefits in a Less Visible Group Domain. Social Psychological and Personality Science, 8(3), 243-251. https://doi.org/10.1177/1948550616671405

Mandalaywala, T. M., Amodio, D. M., \& Rhodes, M. (2018). Essentialism Promotes Racial Prejudice by Increasing Endorsement of Social Hierarchies. Social Psychological and Personality Science, 9(4), 461-469. https://doi.org/10.1177/1948550617707020

Martin, J.W. \& Heiphetz, L. (in press). "Internally Wicked”: Investigating How and Why Essentialism Influences Punitiveness and Moral Condemnation.

Maurer, K. L., Park, B., \& Rothbart, M. (1995). Subtyping versus subgrouping processes in stereotype representation. Journal of Personality and Social Psychology, 69(5), 812-824. https://doi.org/10.1037/0022-3514.69.5.812

McManus, R. M., Kleiman-Weiner, M., \& Young, L. (2020). What We Owe to Family: The Impact of Special Obligations on Moral Judgment. Psychological Science, 31(3), 227-242. https://doi.org/10.1177/0956797619900321

Moodie-Mills, A.C. (2012). Jumping Beyond the Broom: Why Black Gay and Transgender Americans Need More Than Marriage Equality. Center for American Progress.

Retrieved from https://cdn.americanprogress.org/wp-content/uploads/issues/2012/01/pdf/black_lgbt.pdf ?_ga=2.184662633.1375750926.1621262501-1373659476.1621262501.

Nahmias, E. (2011). Intuitions about free will, determinism, and bypassing. 
Nosek, B. A., Banaji, M. R., \& Greenwald, A. G. (2002). Harvesting implicit group attitudes and beliefs from a demonstration web site. Group Dynamics: Theory, Research, and Practice, 6(1), 101-115. https://doi.org/10.1037/1089-2699.6.1.101

Nosek, B. A., \& Smyth, F. L. (2007). A Multitrait-Multimethod Validation of the Implicit Association Test. Experimental Psychology, 54(1), 14-29. https://doi.org/10.1027/1618-3169.54.1.14

Noyes, A., \& Dunham, Y. (2019). Separating kindhood from naturalness: Kinds are diverse in causal structure. PsyArXiv. https://doi.org/10.31234/osf.io/q3zg5

Obergefell v. Hodges, 135 S. Ct. 2071 (Supreme Court 2015).

Ofosu, E. K., Chambers, M. K., Chen, J. M., \& Hehman, E. (2019). Same-sex marriage legalization associated with reduced implicit and explicit antigay bias. Proceedings of the National Academy of Sciences, 116(18), 8846-8851. https://doi.org/10.1073/pnas.1806000116

Olson, K. R., Key, A. C., \& Eaton, N. R. (2015). Gender Cognition in Transgender Children. Psychological Science, 26(4), 467-474. https://doi.org/10.1177/0956797614568156

Onyeador, I. N., Wittlin, N. M., Burke, S. E., Dovidio, J. F., Perry, S. P., Hardeman, R. R., Dyrbye, L. N., Herrin, J., Phelan, S. M., \& van Ryn, M. (2020). The Value of Interracial Contact for Reducing Anti-Black Bias Among Non-Black Physicians: A Cognitive Habits and Growth Evaluation (CHANGE) Study Report. Psychological Science, 31(1), 18-30. https://doi.org/10.1177/0956797619879139

Park, B., Kim, M., \& Young, L. (2019). An examination of accurate versus “ biased” mentalizing in moral and economic decision-making. 
/paper/An-examination-of-accurate-versus- $\%$ E2 $\% 80 \% 9 \mathrm{C}$-biased- $\% \mathrm{E} 2 \% 80 \% 9 \mathrm{D}$-in-and $\underline{\text {-Park-Kim/e6ec8c9240055df4b3078aac61c5704fabafe22f }}$

Park, BoKyung, \& Young, L. (2020). An association between biased impression updating and relationship facilitation: A behavioral and fMRI investigation. Journal of Experimental Social Psychology, 87, 103916. https://doi.org/10.1016/j.jesp.2019.103916

Parker, R. (2009). Sexuality, culture and society: shifting paradigms in sexuality research. Culture, health \& sexuality, 11(3), 251-266.

Pavan v. Smith, 137 S. Ct. 2075 (Supreme Court 2017).

Peretz-Lange, R., \& Muentener, P. (2019). Verbal framing and statistical patterns influence children's attributions to situational, but not personal, causes for behavior. Cognitive Development, 50, 205-221. https://doi.org/10.1016/j.cogdev.2019.05.005

Peretz-Lange, R., \& Muentener, P. (2020). Children's Use of Generic Labels, Discreteness, and Stability to Form a Novel Category. Journal of Cognition and Development, 21(3), 447-475. https://doi.org/10.1080/15248372.2020.1757452

Pew Research Center. (2010). Most Continue to Favor Gays Serving Openly in Military.

Retrieved August 17, 2020, from

https://www.pewresearch.org/politics/2010/11/29/most-continue-to-favor-gays-servingopenly-in-military/.

Pew Research Center. (2016). Vast majority of Americans know someone who is gay, fewer know someone who is transgender. Retrieved December 14, 2020, from https://www.pewforum.org/2016/09/28/5-vast-majority-of-americans-know-someone-w ho-is-gay-fewer-know-someone-who-is-transgender/. 
Pew Research Center. (2017). Support for Same-Sex Marriage Grows, Even Among Groups That Had Been Skeptical. Retrieved December 18, 2020, from https://www.pewresearch.org/politics/2017/06/26/support-for-same-sex-marriage-grows -even-among-groups-that-had-been-skeptical/.

Pew Research Center. (2019). Attitudes on Same-Sex Marriage. Retrieved December 18, 2020, from https:/www.pewforum.org/fact-sheet/changing-attitudes-on-gay-marriage/.

Pew Research Center. (2019). In a Politically Polarized Era, Sharp Divides in Both Partisan Coalitions. Retrieved December 18, 2020, from https://www.pewresearch.org/politics/2019/12/17/in-a-politically-polarized-era-sharp-di vides-in-both-partisan-coalitions/.

Pew Research Center. (2020). 2020 Election Reveals Two Broad Voting Coalitions Fundamentally at Odds. Retrieved December 18, 2020, from https://www.pewresearch.org/fact-tank/2020/11/06/2020-election-reveals-two-broad-vo $\underline{\text { ting-coalitions-fundamentally-at-odds/. }}$

Pew Research Center. (2020). The Global Divide on Homosexuality Persists. Retrieved December 18, 2020, from https://www.pewresearch.org/global/2020/06/25/global-divide-on-homosexuality-persis $\underline{\mathrm{ts} /}$.

Pinker, S. (2005). Edge: The Science of Gender and Science. https://www.edge.org/3rd_culture/debate05/debate05 index.html.

Prinz, J. (2011). Against Empathy. The Southern Journal of Philosophy, 49(s1), 214-233. https://doi.org/10.1111/j.2041-6962.2011.00069.x 
Puar, J. K. (Author). (2018). Terrorist Assemblages: Homonationalism in Queer Times. Duke University Press.

Public Religion Research Institute. (2020). Broad Support for LGBT Rights Across All 50 States. Retrieved December 18, 2020, from https://www.prri.org/wp-content/uploads/2020/04/PRRI_Mar_2020_LGBT-2.pdf.

Rae, J. R., Gülgöz, S., Durwood, L., DeMeules, M., Lowe, R., Lindquist, G., \& Olson, K. R. (2019). Predicting Early-Childhood Gender Transitions. Psychological Science, 30(5), 669-681. https://doi.org/10.1177/0956797619830649

Rhodes, M., Leslie, S.-J., \& Tworek, C. M. (2012). Cultural transmission of social essentialism. Proceedings of the National Academy of Sciences, 109(34), 13526-13531. https://doi.org/10.1073/pnas. 1208951109

Richards, Z., \& Hewstone, M. (2001). Subtyping and Subgrouping: Processes for the Prevention and Promotion of Stereotype Change. Personality and Social Psychology Review, 5(1), 52-73. https://doi.org/10.1207/S15327957PSPR0501 4

Roberts, S. O., Ho, A. K., Rhodes, M., \& Gelman, S. A. (2017). Making Boundaries Great Again: Essentialism and Support for Boundary-Enhancing Initiatives. Personality and Social Psychology Bulletin, 43(12), 1643-1658.

https://doi.org/10.1177/0146167217724801

Roediger, D. R. (2005). Working toward Whiteness: How America's Immigrants Became White: The Strange Journey from Ellis Island to the Suburbs (New York: Basic).

Schein, C., \& Gray, K. (2018). The Theory of Dyadic Morality: Reinventing Moral Judgment by Redefining Harm. Personality and Social Psychology Review, 22(1), 32-70. https://doi.org/10.1177/1088868317698288 
Solomon, A. (2012). Far From the Tree: Parents, Children and the Search for Identity. Simon and Schuster.

Spitzer, R. L. (1981). The diagnostic status of homosexuality in DSM-III: A reformulation of the issues. The American Journal of Psychiatry, 138(2), 210-215. https://doi.org/10.1176/ajp.138.2.210

Steffens, M. C. (2005). Implicit and Explicit Attitudes Towards Lesbians and Gay Men. Journal of Homosexuality, 49(2), 39-66. https://doi.org/10.1300/J082v49n02 03

Steffens, M. C., \& Buchner, A. (2003). Implicit Association Test: Separating transsituationally stable and variable components of attitudes toward gay men. Experimental Psychology, 50(1), 33-48. https://doi.org/10.1026/1618-3169.50.1.33

Strolovitch, D. Z., \& Crowder, C. Y. (2018). Respectability, anti-respectability, and intersectionally responsible representation. PS, Political Science \& Politics, 51(2), 340.

Summers, L.H. (2005). Remarks at NBER Conference on Diversifying the Science \& Engineering Workforce. Harvard University. https://www.harvard.edu/president/speech/2005/remarks-nber-conference-on-diversifyi ng-science-engineering-workforce.

Supiano, B. (2015). Racial Disparities in Higher Education: An Overview. Chronicle of Higher Education. Retrieved December 18, 2020, from https://www.chronicle.com/article/racial-disparities-in-higher-education-an-overview/.

The Matthew Shepard And James Byrd, Jr., Hate Crimes Prevention Act Of 2009. (2015, August $6)$. https://www.justice.gov/crt/matthew-shepard-and-james-byrd-jr-hate-crimes-prevention $\underline{-a c t-2009-0}$ 
The Williams Institute. (2016). How many adults identify as transgender in the United States?

$\underline{\text { Retrieved from }}$

https://williamsinstitute.law.ucla.edu/wp-content/uploads/Trans-Adults-US-Aug-2016.p

df.

Totenberg, N. (2020). Justice Thomas, Alito Blast Supreme Court Decision on Same-Sex

Marriage Rights. National Public Ratio. Retrieved December 18, 2020, from

https://www.npr.org/2020/10/05/920416357/justices-thomas-alito-blast-supreme-court-

decision-on-gay-marriage-rights.

United States Department of Justice, Federal Bureau of Investigation. ( 2019). Hate Crime Statistics, 2018. Retrieved August 17, /2020, from https://ucr.fbi.gov/hate-crime/2018.

Victory Institute. (2020). Out for America Census 2020. Retrieved December 18, 2020, from https://victoryinstitute.org/out-for-america-2020/.

VL v. EL, 136 S. Ct. 1017 (Supreme Court 2016).

Wells, K. (2012, July 5). NoHomophobes.com. Retrieved August 17, 2020, from http://www.nohomophobes.com/.

Wittlin, N. M., Dovidio, J. F., Burke, S. E., Przedworski, J. M., Herrin, J., Dyrbye, L., Onyeador, I. N., Phelan, S. M., \& van Ryn, M. (2019). Contact and role modeling predict bias against lesbian and gay individuals among early-career physicians: A longitudinal study. Social Science \& Medicine, 238, 112422.

https://doi.org/10.1016/j.socscimed.2019.112422

Wright, J. C. (2012). Children's and adolescents' tolerance for divergent beliefs: Exploring the cognitive and affective dimensions of moral conviction in our youth. British Journal of 
Developmental Psychology, 30(4), 493-510.

https://doi.org/10.1111/j.2044-835X.2011.02058.X

Yam, K. C., Fehr, R., Burch, T. C., Zhang, Y., \& Gray, K. (2019). Would I Really Make a Difference? Moral Typecasting Theory and its Implications for Helping Ethical Leaders. Journal of Business Ethics, 160(3), 675-692. https://doi.org/10.1007/s10551-018-3940-0

Zagefka, H., Nigbur, D., Gonzalez, R., \& Tip, L. (2013). Why does ingroup essentialism increase prejudice against minority members? International Journal of Psychology, 48(1), 60-68. https://doi.org/10.1080/00207594.2012.729841

Zaki, J. (2014). Empathy: A motivated account. Psychological Bulletin, 140(6), 1608-1647. https://doi.org/10.1037/a0037679

Zaveri, M. (2020). Utah is Latest State to Ban Conversion Therapy for Children. The New York Times Company. Retrieved December 18, 2020, from https://www.nytimes.com/2020/01/22/us/utah-conversion-therapy-ban.html.

Zebrowitz, L. A. (1996). Physical appearance as a basis of stereotyping. Stereotypes and stereotyping, 79-120. 